\title{
Anthocyanin-rich purple potato flake extract has antioxidant capacity and improves antioxidant potential in rats
}

\author{
Kyu-Ho Han ${ }^{1}$, Mitsuo Sekikawa ${ }^{1}$, Ken-ichiro Shimada ${ }^{1}$, Makoto Hashimoto ${ }^{1}$, Naoto Hashimoto ${ }^{2}$, \\ Takahiro Noda ${ }^{2}$, Hisashi Tanaka ${ }^{3}$ and Michihiro Fukushima ${ }^{1} *$ \\ ${ }^{1}$ Department of Agriculture and Life Science, Obihiro University of Agriculture and Veterinary Medicine, \\ Obihiro, Hokkaido 080, Japan \\ ${ }^{2}$ Department of Upland Agriculture, National Agricultural Research Center for Hokkaido Region, \\ Memuro, Kasai, Hokkaido 082, Japan \\ ${ }^{3}$ Somatech Center, House Foods Corporation, 1-4 Takanodai, Yotsukaido, Chiba 284, Japan
}

(Received 29 March 2006 - Revised 10 July 2006 - Accepted 14 July 2006)

\begin{abstract}
Anthocyanins from various vegetables and fruits have antioxidant activities, however, the bioactivities of coloured potato anthocyanins are not well studied. We examined the antioxidant capacities of pigmented fractions from purple potato flakes in vitro, and the antioxidant potentials of purple potato flakes in vivo. 1,1-Diphenyl-2-picrylhydrazyl radical scavenging activity of the pigmented fraction from Hokkai no. 92 (H92) potato flakes was higher than that from Kitamurasaki (KM) potato flakes. Extracts equivalent to $600 \mu \mathrm{g}$ pigmented fractions from $\mathrm{KM}$ and H92 potato flakes inhibited linoleic acid oxidation in the order trolox $>$ H92 $\geq \mathrm{KM}>$ control. Rats were fed $25 \% \mathrm{KM}$ or H92 potato flake diets for 4 weeks. The major anthocyanin was identified as petanin. Control rats were fed a diet with cornstarch instead of potato flakes for 4 weeks. The serum antioxidant potential level in the H92 group was significantly higher than that in the control group. The degree of hepatic lipid peroxidation in the $\mathrm{H} 92$ group was significantly lower than that in the control group. Hepatic Cu/Zn-superoxide dismutase (SOD), Mn-SOD and glutathione peroxidase (GSH-Px) mRNA levels in the H92 group were significantly higher than those in the control group. Similar significant differences in $\mathrm{Cu} / \mathrm{Zn}-\mathrm{SOD}$ and $\mathrm{Mn}$-SOD mRNA levels between the KM and control groups were found. The present results suggest that purple potato flakes have antioxidant functions with regard to radical scavenging activity and inhibition of linoleic acid oxidation, and that they improve the antioxidant potentials in rats by enhancing hepatic Mn-SOD, Cu/Zn-SOD and GSH-Px mRNA expression.
\end{abstract}

Purple potato flakes: Anthocyanins: Kitamurasaki: Hokkai no. 92: Antioxidant activity: Antioxidant enzymes

Anthocyanins are natural colourants derived from many flowers, fruits, vegetables and legumes. They are present exclusively as glycosidic compounds in plants (Harborne \& Grayer, 1988). Depending on the $\mathrm{pH}$, pigments of anthocyanins are red to purple or blue. Recently, anthocyanins have attracted interest in the food industry as safe and effective food colourants, and their consumption is on the increase as concentrated blueberry, elderberry and red grape extracts are commercially available. Several researchers have reported that anthocyanins have remarkable antioxidant and free radical scavenging activities (Wang et al. 1997; Tsuda et al. 2000), and can inhibit LDL oxidation in vitro (Kähkönen \& Heinonen, 2003), findings which suggest that anthocyanin contents of berries, grapes and the purple sweet potato may provide possible health benefits such as reduction of CHD (Zern et al. 2005), anti-inflammatory activity (Afaq et al. 2005) and anticancer activity (Hagiwara et al. 2002). An epidemiological study has also indicated that intakes of anthocyanin-rich fruits and vegetables are related to health benefits (Omenn, 1995).
Potato cultivars (Solanum tuberosum L.) are one of the most widely grown high carbohydrate crops in the world. In general, potatoes have not been regarded as being rich in antioxidants. However, depending on the genetic variety, they can contain considerable amounts of polyphenols, flavonoids, anthocyanins or ascorbic acid (vitamin C) (Augustin, 1975; Lewis et al. 1998; Brown, 2005). Recently, new potato varieties have been shown to be rich in antioxidants. Among these, coloured potatoes have attracted special interest in many countries (Johnson, 1995) due to their colour appeal and excellent taste (Sorenson, 1992). Several researchers have studied the anthocyanin contents of coloured potato tubers. The pigments have been identified as anthocyanin derivatives (Lewis et al. 1998; RodriguezSaona et al. 1998; Eichhorn \& Winterhalter, 2005). In fact, the first anthocyanin in a coloured potato, malvidin-3-( $p$-coumaroryl-rutinoside)-5-glucose, was identified by Chmielewska (1936) in the 1930s. Like anthocyanins from other plants, it has been suggested that analogous potato anthocyanins may also be important functional foods (Brown, 2005). We have recently

Abbreviations: DPPH, 1,1-diphenyl-2-picrylhydrazyl; GADPH, glyceraldehyde-3-phosphate dehydrogenase; GSH-Px, glutathione peroxidase; GSH-R, glutathione reductase; H92, Hokkai no. 92; KM, Kitamurasaki; OD, optical density; SOD, superoxide dismutase; TBARS, thiobarbituric acid reactive substances; trolox, 6hydroxy-2,5,7,8-tetramethyl-chroman-2-carboxylic acid.

* Corresponding author: Dr Michihiro Fukushima, fax +81 15549 5577, email fukushim@obihiro.ac.jp 
reported that purple potato extract prevents the liver injury induced by D-galactosamine in rats (Han et al. 2006). However, less well appreciated is the bioavailability of anthocyanins found in coloured potatoes, which may act as antioxidants in the human diet.

In the present study, we investigated the antioxidant effects of pigmented fractions prepared from Kitamurasaki (KM) and Hokkai no. 92 (H92) potato flakes on radical scavenging activity and linoleic acid oxidation in vitro. Furthermore, we examined the antioxidant effects of those potato flakes on serum antioxidant potential, hepatic lipid peroxidation and hepatic mRNA in rats.

\section{Materials and methods}

\section{Chemicals}

Trolox (6-hydroxy-2,5,7,8-tetramethyl-chroman-2-carboxylic acid), TCA, butylated hydroxytoluene, bovine serum albumin and thiobarbituric acid were purchased from Sigma Chemical Co. (St Louis, MO, USA). 2,2'-Azobis (2-amidinopropane) dihydrochloride and 1,1-diphenyl-2-picrylhydrazyl (DPPH) were obtained from Wako Pure Chemicals Industries (Osaka, Japan).

\section{Preparation of potato flakes and pigmented fractions}

Purple potato flakes of KM (light purple) and H92 (mediumdark purple) were a kind gift from Somatech Center, House Foods Corporation, Japan. The preparation of potato flakes was as follows: KM and H92 potatoes were thoroughly washed with water and air dried on filter paper, and then they were peeled and sliced. The sliced potatoes were treated with steam blanching to minimize enzymatic reactions that bring out degrading anthocyanins. Next, they were mashed and dried in a drum dryer, and finally ground to flakes.

For preparation of pigmented fractions, $50 \mathrm{~g}$ potato flakes were subjected to extraction by exposure to $5 \%$ acetic acid three times overnight at room temperature. The suspension was centrifuged at $5500 \mathrm{~g}$ for $20 \mathrm{~min}$, and extraction from the resultant precipitate was done under the same conditions. Again the supernatant was centrifuged at $28400 \mathrm{~g}$ for $30 \mathrm{~min}$. The upper layer was separated and directly applied on to Diaion HP-20 resin (Nippon Rensui Co., Tokyo, Japan). Sugars, proteins and salts were removed by washing the column with $1 \%$ acetic acid. Anthocyanin was retained by the resin and finally eluted with a mixture of $70 \%$ ethanol. Ethanol was removed using a rotary evaporator at $35^{\circ} \mathrm{C}$, and the eluate was diluted with water and lyophilized to give anthocyanin-rich pigmented fractions.

\section{Identification of anthocyanins from pigmented fraction}

Anthocyanin pigments were analysed using HPLC, liquid chromatography-MS, and ${ }^{1} \mathrm{H}$ and ${ }^{13} \mathrm{C}$ NMR. Analytical HPLC was carried out using an LC-10AD pump system (Shimadzu, Kyoto, Japan) and a TSKgel ODS-80Ts column $(4.6 \mathrm{~mm} \times 250 \mathrm{~mm}$; Tosoh, Tokyo, Japan) with a flow rate of $1.0 \mathrm{ml} / \mathrm{min}$ and monitoring at $360 \mathrm{~nm}$ (SPD-10A wavelength detector; Shimadzu). The solvent system was composed of water, methanol and trifluoroacetic acid (70:30:0.1, by vol.). The molecular weights of the major peaks were determined by liquid chromatography-MS (ZQ 2000; Waters, Milford, MA, USA) using the same HPLC conditions as above. The major peaks on the HPLC that were collected by preparative HPLC were used for ${ }^{1} \mathrm{H}$ and ${ }^{13} \mathrm{C}$ NMR analyses (ECA500; JEOL, Tokyo, Japan) to determine the chemical structures.

\section{Dietary fibre and micronutrient contents}

Dietary fibre, protein, lipid, carbohydrate, moisture and ash in KM and H92 potato flakes were determined by the Association of Official Analytical Chemists (1990) procedure.

\section{Total polyphenol contents}

Total polyphenol concentrations in KM and $\mathrm{H} 92$ potato flakes were determined by the Folin-Ciocalteu method (Singleton et al. 1998). The absorbance was measured at $750 \mathrm{~nm}$ using a Shimadzu 1600-UV spectrophotometer. Total phenolic contents of pigmented fractions from KM and $\mathrm{H} 92$ potato flakes were converted into $\mathrm{mg}$ gallic acid equivalents per $100 \mathrm{~g}$ powder weight.

\section{Flavonoid contents}

The absorbance of flavonoids was measured at $510 \mathrm{~nm}$ with standards based on the known $(+)$-catechin concentration (Jia et al. 1999). Flavonoid contents of pigmented fractions from KM and $\mathrm{H} 92$ potato flakes were converted into mg catechin equivalents per $100 \mathrm{~g}$ powder weight.

\section{Total anthocyanin contents}

The amounts of monomeric anthocyanins were measured by a pH differential method (Giusti \& Wrolstad, 2001). A Shimadzu 1600-UV spectrophotometer was used to measure the absorbance at 525 and $700 \mathrm{~nm}$ in buffer at $\mathrm{pH} 1.0$ and 4.5. Anthocyanin contents were calculated using the molar extinction coefficient of cyanidin 3-glucoside (26900 1/cm per mg) and absorbance $A=\left[\left(A_{525}-A_{700}\right)_{\mathrm{pH} 1 \cdot 0}-\left(A_{525}-A_{700}\right)_{\mathrm{pH} 4 \cdot 5}\right]$. Anthocyanin contents of pigmented fractions from $\mathrm{KM}$ and H92 potato flakes were converted into $\mathrm{mg}$ per $100 \mathrm{~g}$ powder weight.

\section{Radical scavenging activity and inhibition of linoleic acid oxidation}

DPPH is a radical-generating substrate widely used to monitor the free radical scavenging abilities of various antioxidants (Brand-Williams et al. 1995). First, $0.3 \mathrm{ml}$ of various concentrations of pigmented-fraction solutions $(0-100 \mu \mathrm{g})$ from KM and $\mathrm{H} 92$ potato flakes was mixed with $0.9 \mathrm{ml}$ of a solution containing $0.3 \mathrm{ml} 0.4 \mathrm{~mm}-\mathrm{DPPH}$ in ethanol, MES buffer $(\mathrm{pH} 4.5)$ and $20 \%$ ethanol. Then the mixture was shaken vigorously and left to stand for $30 \mathrm{~min}$. The optical density (OD) of the solution was then measured at $520 \mathrm{~nm}$, and radical scavenging activity was obtained from the following equation: Radical scavenging activity $(\%)=\left(\mathrm{OD}_{\text {control }}-\right.$ $\left.\mathrm{OD}_{\text {sample }}\right) / \mathrm{OD}_{\text {control }} \times 100$, where $\mathrm{OD}_{\text {sample }}$ represents the absorption of the sample solution, and $\mathrm{OD}_{\text {control }}$ is that for the control solution (not containing the sample). 
Linoleic acid oxidation was done by a modification of the method of Mitsuda et al. (1996). In brief, $4 \mathrm{ml} 0.03 \%$ potato pigmented fraction solution from KM or $\mathrm{H} 92$ potato flakes was mixed with $40 \mathrm{ml} 30 \mathrm{~mm}$-linoleic acid substrate in $0.1 \mathrm{M}$ phosphate buffer ( $\mathrm{pH} 7 \cdot 0)$-ethanol $(4: 1, \mathrm{v} / \mathrm{v})$, and incubated at $40^{\circ} \mathrm{C}$ for $0,1,2,4$ and $5 \mathrm{~d}$. Control groups were treated with $4 \mathrm{ml}$ distilled water or $0.03 \%$ trolox solution. Fractions $(2 \mathrm{ml})$ from substrate solutions were obtained in every $24 \mathrm{~h}$ period and mixed with $1 \mathrm{ml} 20 \%$ TCA and $2 \mathrm{ml} 0.67 \%$ thiobarbituric acid in acetic acid. The mixtures were incubated in a boiling water-bath for $15 \mathrm{~min}$. After cooling, $2 \mathrm{ml}$ chloroform were added and the samples were centrifuged at $2000 \mathrm{~g}$ for $10 \mathrm{~min}$. Absorbance of the supernatant was measured at $532 \mathrm{~nm}$ using a Shimadzu 1600-UV spectrophotometer.

\section{Animals and diets}

The experimental design was approved by the Animal Experiment Committee of Obihiro University of Agriculture and Veterinary Medicine. All animal procedures described conformed to National Institutes of Health guidelines (National Research Council, 1996). Male F344/DuCrj rats (8 weeks of age) were purchased from Charles River Japan (Yokohama, Japan). The animal facility was maintained on a $12 \mathrm{~h}$ lightdark cycle at a temperature of $23 \pm 1^{\circ} \mathrm{C}$ and relative humidity of $60 \pm 5 \%$. Animals were randomly assigned into three groups ( $n$ 5). There was no significant difference in body weight at the start of the experiment. Body weight and food consumption were recorded weekly and daily, respectively. The composition of each diet is shown in Table 1. Diets were based on the AIN-93G semi-purified rodent diet (Reeves et al. 1993). Rats were fed KM or $\mathrm{H} 92$ potato flakes at $250 \mathrm{~g} / \mathrm{kg}$ diet for 4 weeks. Control rats were fed a diet with cornstarch instead of potato flakes for 4 weeks. At the end of the experiment, rats were anaesthetized with Nembutal (sodium pentobarbital, $40 \mathrm{mg} / \mathrm{kg}$ body weight; Abbott Laboratories, Abbott Park, IL, USA) and killed. Blood samples were collected and taken into tubes without an anticoagulant. After the samples were allowed to stand at room temperature for $2 \mathrm{~h}$, the sera were separated by centrifugation at $1500 \mathrm{~g}$ for $20 \mathrm{~min}$. The livers were quickly removed,

Table 1. Experimental diets ( $\mathrm{g} / \mathrm{kg}$ diet)*

\begin{tabular}{lccc}
\hline & \multicolumn{3}{c}{ Dietary group } \\
\cline { 2 - 4 } Component & Control & KM & H92 \\
\hline Casein & 200 & 200 & 200 \\
Sucrose & 100 & 100 & 100 \\
Mineral mixture† & 35 & 35 & 35 \\
Vitamin mixture† & 10 & 10 & 10 \\
$\alpha$-Cornstarch & $549 \cdot 486$ & $299 \cdot 486$ & 299.486 \\
Kitamurasaki flakes & - & 250 & - \\
Hokkai no. 92 flakes & - & - & 250 \\
L-Cystine & 3 & 3 & 3 \\
Cellulose powder & 50 & 50 & 50 \\
Soyabean oil & 50 & 50 & 50 \\
Choline bitartrate & 2.5 & 2.5 & 2.5 \\
tert-Butyl hydroquinone & 0.014 & 0.014 & 0.014 \\
\hline
\end{tabular}

H92, Hokkai no. 92 potato flake diet; KM, Kitamurasaki potato flake diet. ${ }^{*}$ For details of diets, see p. 1127.

† Based on the AIN-93G diet composition (Reeves et al. 1993). washed with cold saline $(9 \mathrm{~g} \mathrm{NaCl} / \mathrm{l})$, blotted dry on filter paper and weighed before freezing for storage at $-80^{\circ} \mathrm{C}$.

\section{Trolox equivalent antioxidant coefficient value of serum}

The total antioxidant potentials of sera from rats fed the KM and H92 potato flake diets were determined using a commercial kit (NX 2332; Randox Laboratories, Antrim, $\mathrm{UK}$ ), based on scavenging of 2,2'-azinobis(3-ethylbenzothiazoline-6-sulphonate) radical cations (Re et al. 1999).

\section{Oxidation resistance of liver homogenate}

Liver samples $(0.5 \mathrm{~g})$ were homogenized in 10 volumes of PBS ( $\mathrm{pH} 7 \cdot 4)$. The homogenates were treated with or without 2,2'-azobis (2-amidinopropane) dihydrochloride (final concentration $5 \mathrm{~mm}$ ) at $37^{\circ} \mathrm{C}$ for $1 \mathrm{~h}$ in a shaking water-bath. Then the reaction was stopped by adding butylated hydroxytoluene (final concentration $60 \mu \mathrm{M}$ ). The degree of oxidation was immediately measured by the thiobarbituric acid reactive substances (TBARS) assay (Ohkawa et al. 1979). Protein concentrations were determined by the Bradford assay (Bio-Rad, Hercules, CA, USA) (Bradford, 1976).

\section{RNA isolation, RT-PCR and Southern blot analysis}

Total RNA was isolated from the liver using ISOGEN reagent (Nippon Gene, Tokyo, Japan) according to the manufacturer's protocol (Chomczynski \& Sacchi, 1987). The amounts of mRNA encoding Mn-superoxide dismutase (SOD), Cu/ZnSOD, catalase, glutathione peroxidase (GSH-Px), glutathione reductase (GSH-R) and glycelaldehyde-3-phosphate dehydrogenase (GADPH, as an internal standard) were estimated by semi-quantitative RT-PCR and subsequent Southern blot analysis of PCR products with each inner oligonucleotide probe.

Total RNA samples were treated with DNase RQ1 (Promega, Madison, WI, USA) to remove genomic DNA, and were then subjected to RT-PCR using Moloney murine leukaemia virus RT (Gibco-BRL, Gaithersburg, MD, USA) and EX-Taq polymerase (Takara, Tokyo, Japan) with Mn-SOD primers of oligonucleotides (upstream primer, 5'-CGC TGT CAC TGT CAT CAT AAG-3'; downstream primer, 5'-GTC CGG TGC AGG GCG TCA TTC-3'), Cu/Zn-SOD primers of oligonucleotides (upstream primer, 5'-GTC CGG TGC AGG GCG TCA TTC-3'; downstream primer, 5'-CAA TCA CAC CAC AAG CCA AGC-3'), catalase primers of oligonucleotides (upstream primer, 5'-CTG GTT AAT GCG AAT GGA GAG-3'; downstream primer, 5'-TGG GGT AGT AGT AGT TGG GAG CAC-3'), GSH-Px primers of oligonucleotides (upstream primer, 5'-GCT GAA GGA GGC ACT TGG TCA-3'; downstream primer, 5'-TGA TGT ACT TGG GGT CGG TCA-3'), GSH-R primers of oligonucleotides (upstream primer, 5'-GCC GCA GCG TTA TTG TGG GTG-3'; downstream primer, 5'-CGA TAG GCG GGT GGC TGA AGA C $-3^{\prime}$ ) and GAPDH primers of oligonucleotides (upstream primer, 5'-GCC ATC AAC GAC CCC TTC ATT-3'; downstream primer, 5'-CGC CTG CTT CAC CAC CTT CTT-3'). The reaction mixtures for the PCR contained $25 \mathrm{pmol}$ each primer, 1.25 U EX-Taq polymerase, $1 \times$ PCR buffer (Takara) and $200 \mu \mathrm{mol} / 1 \mathrm{dNTP}$ in a $50 \mu \mathrm{l}$ reaction volume. 
Amplification products were electrophoresed on $2 \%$ agarose gel, and transferred to a nylon membrane (Biodyne B; Pall Bio-Support, East Hills, NY, USA). Blots were hybridized with an Mn-SOD probe of a fifty-three-base oligonucleotide (5'-CAG TCA GGA GCC TAG CTT GGG TCT GTT GAT TTG TTC AGT AGT GAG GTA GAC CC-3'), $\mathrm{Cu} / \mathrm{Zn}$-SOD probe of a fifty-four-base oligonucleotide $\left(5^{\prime}-\right.$ AGC AGC CAC ATT GCC CAG GTC TCC AAC ATG CCT CTC TTC ATC CGC TGG ACC GCC-3'), catalase probe of a fifty-four-base oligonucleotide (5'-AGT TGG CCA CGC GAG CAC GGT AGG GAC AGT TCA CAG GTA TCT GCA GAT AGT TTG-3'), GSH-Px probe of a fifty-four-base oligonucleotide (5'-CCT TCT CAC CAT TCA CCT GGC ACT TCT CAA ACA ATG TAA AGT TGG GCT CGA ACC-3'), GSH-R probe of a fifty-four-base oligonucleotide (5'-ACC ACA TGG AGT TCC AAG CCC GAT GAG GTC TTC TTT ACT TCC TTA ACC TGT GAG- $\left.3^{\prime}\right)$ and GAPDH probe of a fifty-four-base oligonucleotide (5'-TGA TGA CCA GCT TCC CAT TCT CAG CCT TGA CTG TGC CGT TGA ACT TGC CGT GGG-3'). The probes were $3^{\prime}$-tailing labelled with digoxigenin, using a digoxigenin oligonucleotide tailing kit (Boehringer, Mannheim, Germany). Prehybridization, hybridization and detection were carried out with a digoxigenin luminescent detection kit that contained an alkaline phosphatase-conjugated anti-digoxigenin antibody (Boehringer) as recommended by the manufacturer. The relative quantity of mRNA was estimated by densitometry scanning with X-ray film.

\section{Statistical analysis}

Data are presented as means and standard deviations. The significance of differences between two groups was determined by Student's $t$-test. The means and standard deviations for linoleic acid oxidation at prescribed times were calculated. The significance of differences among treatment groups was determined by ANOVA with Duncan's multiple range test (SAS Institute, Cary, NC, USA).

\section{Results}

The yields of pigmented fractions from KM and $\mathrm{H} 92$ potato flakes based on the flake weight were $1.24 \%$ and $1.93 \%$, respectively. The major anthocyanin (over $90 \%$ ) in pigmented fractions from KM and $\mathrm{H} 92$ potato flakes was identified as petunidin-3- $O$-[6- $O$-(4- $O-E$ - $p$-coumaroyl- $O$ - $\alpha$-rhamnopyranosyl)- $\beta$-glucopyranoside]-5-O- $\beta$-glucopyranoside (Fig. 1 ) by comparison with previous reports (Fossen et al. 2003) on ${ }^{13} \mathrm{C}$ and ${ }^{1} \mathrm{H}$ NMR analyses and MS spectroscopy.

The contents of total phenols, flavonoids and anthocyanins in pigmented fractions from KM and $\mathrm{H} 92$ potato flakes are shown in Table 2 . The contents of total phenols in pigmented fractions from KM and H92 potato flakes were 241.7 and $505.4 \mathrm{mg} / 100 \mathrm{~g}$ powder, respectively. The contents of flavonoids of pigmented fractions from $\mathrm{KM}$ and $\mathrm{H} 92$ potato flakes were 65.7 and $131.4 \mathrm{mg} / 100 \mathrm{~g}$ powder, respectively. Moreover, the contents of total monomeric anthocyanins in pigmented fractions from KM and $\mathrm{H} 92$ potato flakes were 55.5 and $213.8 \mathrm{mg} / 100 \mathrm{~g}$ powder, respectively. All contents of total phenols, flavonoids and anthocyanins in the pigmented fraction from $\mathrm{H} 92$ potato flakes were higher than those in the pigmented fraction from KM potato flakes.

DPPH radical scavenging activities of pigmented fractions from KM and $\mathrm{H} 92$ potato flakes were expressed as the OD of $0.4 \mathrm{~mm}$-DPPH solution (Fig. 2(A)) and as the effective dose $\left(\mathrm{EC}_{50}\right)$ for scavenging $50 \%$ of the DPPH radicals (Fig. 2(B)). A lower $\mathrm{EC}_{50}$ shows higher radical scavenging activity. The amount of trolox required for $\mathrm{EC}_{50}$ was $28.9 \mu \mathrm{g} / \mathrm{ml}$. H92 had a lower $\mathrm{EC}_{50}$ for DPPH radical scavenging activity $(110 \cdot 1 \mu \mathrm{g} /$ $\mathrm{ml})$ than $\mathrm{KM}\left(\mathrm{EC}_{50}=164.6 \mu \mathrm{g} / \mathrm{ml}\right)$. The pigmented fractions from KM and $\mathrm{H} 92$ potato flakes most successfully suppressed the linoleic acid oxidation (Fig. 3). The inhibition of linoleic acid oxidation by the equivalent of $300 \mu \mathrm{g} / \mathrm{ml}$ samples was higher in the order trolox $>\mathrm{H} 92 \geq \mathrm{KM}>$ control.

Food intakes, body weight gains and liver weights of rats in $\mathrm{KM}$ and $\mathrm{H} 92$ groups were not significantly different from those in the control group (Table 3). However, body weight
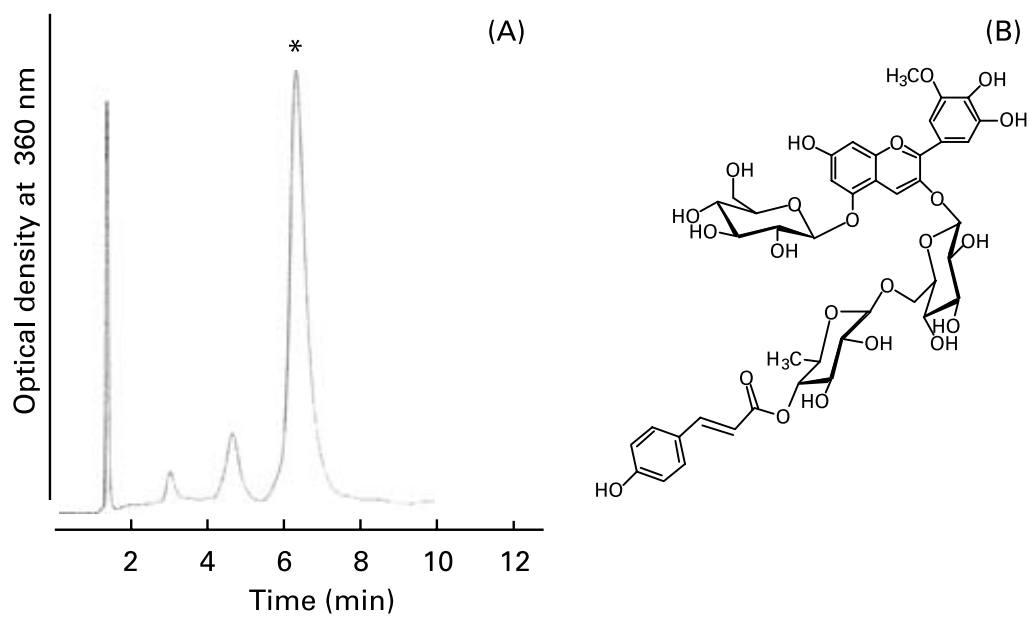

Fig. 1. HPLC chromatogram (A) of purified anthocyanin from pigmented fractions of Kitamurasaski and Hokkai no. 92 potato flakes, and the structure (B) of the main anthocyanin from both Kitamurasaski and Hokkai no. 92 potato flakes. The column was conditioned with water-methanol-trifluroacetic acid (70:30:0-1, by

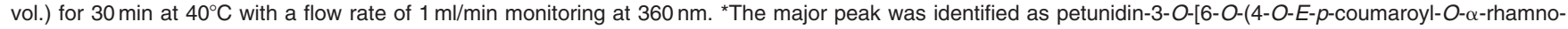
pyranosyl)- $\beta$-glucopyranoside]-5-O- $\beta$-glucopyranoside. 
Table 2. Micronutrient and antioxidant contents ( $\mathrm{g} / 100 \mathrm{~g}$ powder) in purple potato flakes $\dagger$

\begin{tabular}{|c|c|c|}
\hline & $\begin{array}{l}\text { KM flakes } \\
\text { (light purple) }\end{array}$ & $\begin{array}{c}\text { H92 flakes } \\
\text { (medium-dark purple) }\end{array}$ \\
\hline Water & $5 \cdot 2$ & $5 \cdot 7$ \\
\hline Protein & $5 \cdot 8$ & $7 \cdot 6$ \\
\hline Lipid & 0.4 & 0.5 \\
\hline Carbohydrate & 84.6 & $82 \cdot 0$ \\
\hline Soluble fibre & $2 \cdot 6$ & $2 \cdot 3$ \\
\hline Insoluble fibre & 3.2 & 3.5 \\
\hline Ash & 4.0 & $4 \cdot 2$ \\
\hline Polyphenols (gallic acid, mg/100 g) & $241 \cdot 7$ & $505 \cdot 4$ \\
\hline Flavonoids (catechin, $\mathrm{mg} / 100 \mathrm{~g}$ ) & 65.7 & 131.4 \\
\hline Anthocyanins (mg/100 g) & $55 \cdot 5$ & $213 \cdot 8$ \\
\hline
\end{tabular}

H92, Hokkai no. 92; KM, Kitamurasaki.

†For details of procedures, see pp. 1126-1127.

gain in the H92 group was significantly $(P<0 \cdot 05)$ lower than in the KM group.

The total antioxidant capacities measured as Randox trolox equivalent antioxidant capacity in sera of rats fed the control, KM and H92 potato flake diets over a period of 4 weeks are shown in Fig. 4. Serum antioxidant potential in the KM group was similar to that in the control group, whereas the serum antioxidant potential in the $\mathrm{H} 92$ group was significantly $(P<0 \cdot 05)$ higher than in the control group.

The TBARS levels from hepatic homogenates of control, KM and H92 groups are shown in Fig. 5. The hepatic TBARS level in the KM group was slightly lower than that in the control group; however, there was no significant difference, whereas the hepatic TBARS level in the H92 group was significantly $(P<0.01)$ lower than that in control group (Fig. 5(A)). Susceptibility to lipid peroxidation in hepatic homogenates from the control and $\mathrm{H} 92$ groups was induced by $2,2^{\prime}$-azobis (2-amidinopropane) dihydrochloride at $37^{\circ} \mathrm{C}$ for $1 \mathrm{~h}$. The hepatic TBARS level in the H92 group was slightly but significantly $(P<0.05)$ lower than that of the control group (Fig. 5(B)).

The relative quantities of mRNA were determined by Southern hybridization of PCR-amplified Mn-SOD, Cu/
Zn-SOD, catalase, GSH-Px and GSH-R cDNA in the rat liver. The values of $\mathrm{Mn}-\mathrm{SOD}, \mathrm{Cu} / \mathrm{Zn}-\mathrm{SOD}$, catalase, GSHPx and GSH-R mRNA were expressed relative to the value of GAPDH mRNA in all groups (Fig. 6). The relative hepatic Mn-SOD, Cu/Zn-SOD and GSH-Px mRNA levels in the H92 group were significantly $(P<0.01, P<0.05$ and $P<0.05$, respectively) higher than those in the control group. Significant $(P<0.05)$ differences in $\mathrm{Mn}-\mathrm{SOD}$ and $\mathrm{Cu} / \mathrm{Zn}-\mathrm{SOD}$ mRNA levels between the KM and control groups were also found. However, there were no significant differences in hepatic catalase and GSH-R mRNA levels among the groups.

\section{Discussion}

The first distinct study of anthocyanin in potatoes was reported in 1936, and the first identified anthocyanin in the potato was malvidin-3-( $p$-coumaroryl-rutinoside)-5-glucose (Chmielewska, 1936). Thereafter, potato tubers were found to have various anthocyanins, depending on the genetic variety, such as malvidin, peonidin, pelagonidin and petunidin (Brown, 2005; Eichhorn \& Winterhalter, 2005). Recently, Lewis et al. (1998) reported that light to medium purple potato tubers contained petunidin together with smaller concentrations of
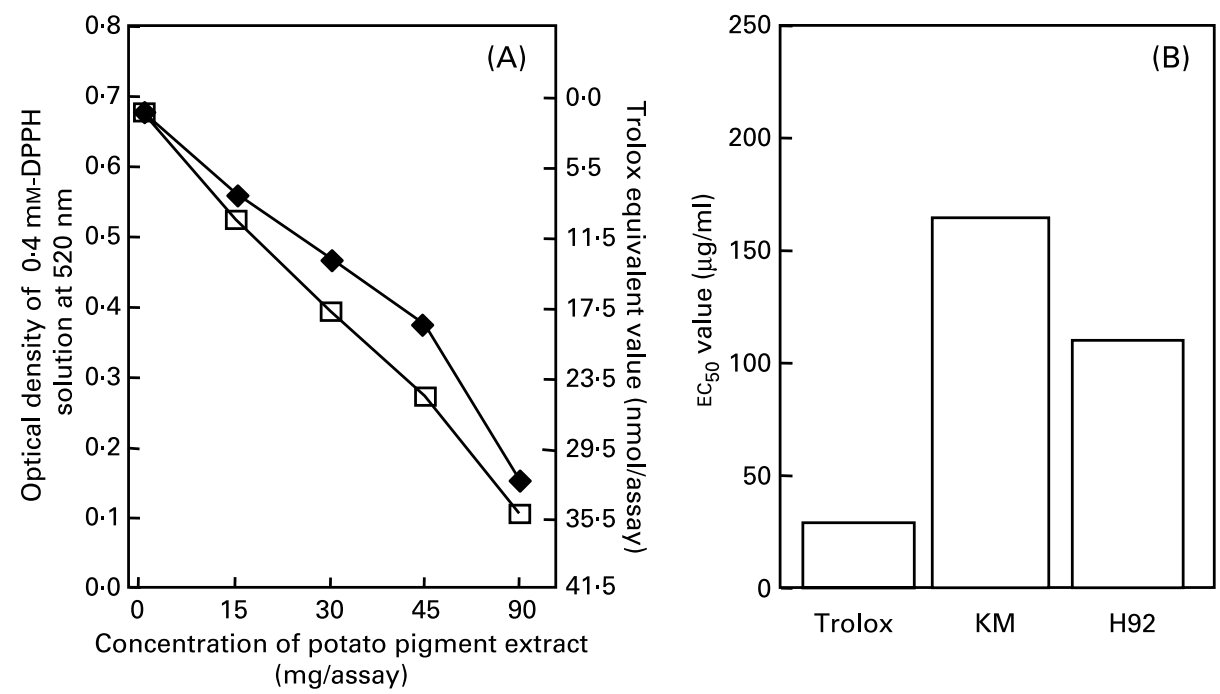

Fig. 2. 1,1-Diphenyl-2-picrylhydrazyl (DPPH) radical scavenging activities of purple-pigment fractions from Kitamurasaki (KM) and Hokkai no. 92 (H92) potato flakes expressed as the OD of $0.4 \mathrm{mM}-\mathrm{DPPH}$ solution $(\mathrm{A})(\diamond, \mathrm{KM} ; \square, \mathrm{H} 92)$ and as the effective dose (EC $\left.\mathrm{E}_{50}\right)$ for scavenging $50 \%$ of the DPPH radicals (B). For details of procedures, see pp. 1126-1127. Trolox, 6-hydroxy-2,5,7,8-tetramethyl-chroman-2-carboxylic acid. 


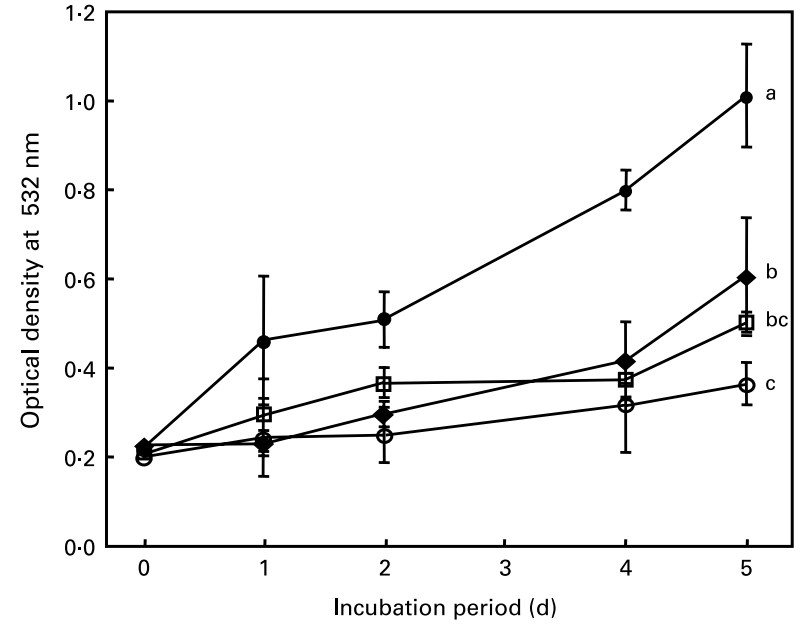

Fig. 3. Antioxidant effects of purple-pigment fractions from Kitamurasaki (KM) and Hokkai no. 92 (H92) potato flakes on linoleic acid oxidation. Mixtures were incubated at $40^{\circ} \mathrm{C}$ for $0,1,2,4$ and $5 \mathrm{~d}$. Each of the fractions from substrate solutions $(n 3)$ was obtained in every $24 \mathrm{~h}$ period. For details of procedures, see pp. 1126-1127. Values are means with their standard deviations depicted by vertical bars. • , control; ○, 6-hydroxy-2,5,7,8-tetramethylchroman-2-carboxylic acid (trolox); $\bullet$, 0.03\% KM; $\square, 0.03 \%$ H92. ${ }^{\text {a,b,c }}$ Mean values with unlike superscript letters were significantly different $(P<0.05)$.

malvidin, while dark purple-black tubers contained petunidin together with much higher concentrations of malvidin. In the present study, the pigmented fractions from both KM and H92 potato flakes mostly contained petunidin, which were similar findings to the results of Fossen et al. (2003) and Lewis et al. (1998).

Some studies have indicated that phenolic compounds in coloured potatoes have antioxidant activities in vitro (Brown, 2005; Reyes et al. 2005). In this study, the pigmented fractions from both KM and H92 potato flakes had antioxidant activities. The antioxidant capacity of the pigmented fraction from $\mathrm{H} 92$ potato flakes was higher than that of the pigmented fraction from KM potato flakes with regard to radical scavenging activity $\left(\mathrm{H} 92, \quad \mathrm{EC}_{50}=110 \cdot 1 \mu \mathrm{g} / \mathrm{ml}\right.$ and scope $=-0.0062 ; \mathrm{KM}$, $\mathrm{EC}_{50}=164.6 \mu \mathrm{g} / \mathrm{ml}$ and scope $\left.=-0.0057\right)$. This difference might have been due to the higher concentrations of phenolic constituents in the pigmented fraction from $\mathrm{H} 92$ potato flakes as the concentration of monomeric anthocyanins in the extract equivalent to the pigmented fraction from H92 potato flakes

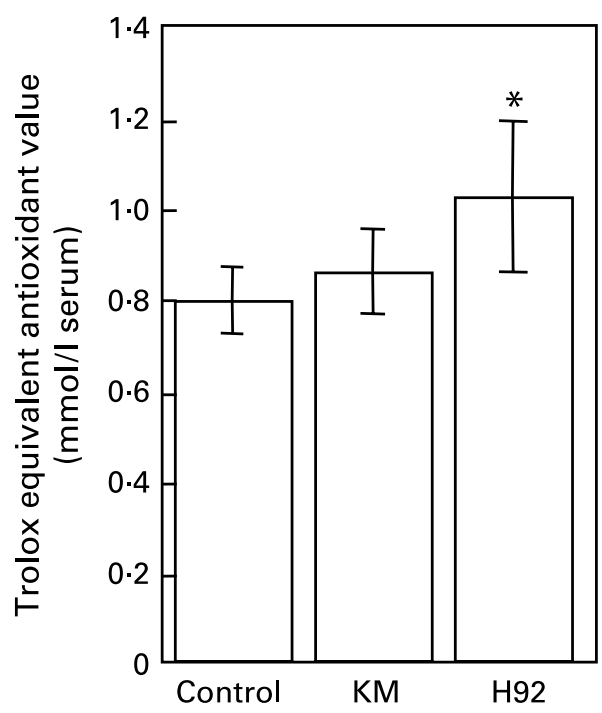

Fig. 4. Total antioxidant potentials of sera from rats fed the basal (control), Kitamurasaki (KM) and Hokkai no. 92 (H92) potato flake diets for 4 weeks determined by scavenging of 2,2'-azinobis(3-ethylbenzothiazoline-6-sulphonate) radical cations. For details of procedures and diets, see pp. 11261127 and Table 1. Values are means with their standard deviations depicted by vertical bars (data obtained from five animals). Mean value was significantly different from that of the control group (Student's $t$ test): * $P<0.05$. Trolox, 6-hydroxy-2,5,7,8-tetramethyl-chroman-2-carboxylic acid.

(111 $\mu \mathrm{g} / \mathrm{mg})$ was higher than that in the pigmented fraction from $\mathrm{KM}$ potato flakes $(45 \mu \mathrm{g} / \mathrm{mg}$ ). Furthermore, the concentration of total polyphenols in the extract equivalent to the pigmented fraction from $\mathrm{H} 92$ potato flakes $(262 \mu \mathrm{g} / \mathrm{mg})$ was higher than that in the pigmented fraction from KM potato flakes $(195 \mu \mathrm{g} / \mathrm{mg})$.

We also investigated the antioxidant effects of purple potato flakes in vivo, and found that H92 potato flakes enhanced the serum trolox equivalent antioxidant capacity values and suppressed hepatic TBARS levels in rats. Several researchers have reported that consumption of anthocyanins leads to increases in serum antioxidant potential in experimental animals (Auger et al. 2004) as well as in human subjects (Cao et al. 1998; Pedersen et al. 2000; Mazza et al. 2002). Furthermore, RamirezTortosa et al. (2001) reported that an anthocyanin-rich extract decreased hepatic lipid peroxidation in vitamin E-depleted rats. The present findings suggest that the anthocyanin-rich

Table 3. Body weight, food intake and liver weight in rats fed Kitamurasaki and (KM) Hokkai no. 92 (H92) potato flakes for 4 weekst

(Mean values and standard deviations for five rats per group)

\begin{tabular}{|c|c|c|c|c|c|c|}
\hline & \multicolumn{6}{|c|}{ Dietary groups } \\
\hline & \multicolumn{2}{|c|}{ Control } & \multicolumn{2}{|c|}{$\mathrm{KM}$} & \multicolumn{2}{|c|}{$\mathrm{H} 92$} \\
\hline & Mean & SD & Mean & SD & Mean & SD \\
\hline Initial body weight $(\mathrm{g})$ & 187 & 3 & 187 & 3 & 186 & 4 \\
\hline Body weight gain (g/4 weeks) & $67 \cdot 3$ & $7 \cdot 0$ & $68 \cdot 3$ & $4 \cdot 2$ & $60 \cdot 6^{*}$ & $5 \cdot 6$ \\
\hline Food intake (g/4 weeks) & 448 & 26 & 459 & 18 & 450 & 29 \\
\hline Liver weight $(\mathrm{g})$ & $8 \cdot 70$ & 0.61 & 8.57 & 0.70 & 8.49 & 0.89 \\
\hline Liver weight (g/100 g body weight) & 3.42 & $0 \cdot 22$ & $3 \cdot 35$ & $0 \cdot 21$ & 3.44 & 0.27 \\
\hline
\end{tabular}

Mean value was significantly different from that of the KM group: ${ }^{*} P<0.05$.

†For details of diets and procedures, see pp. 1126-1127. 

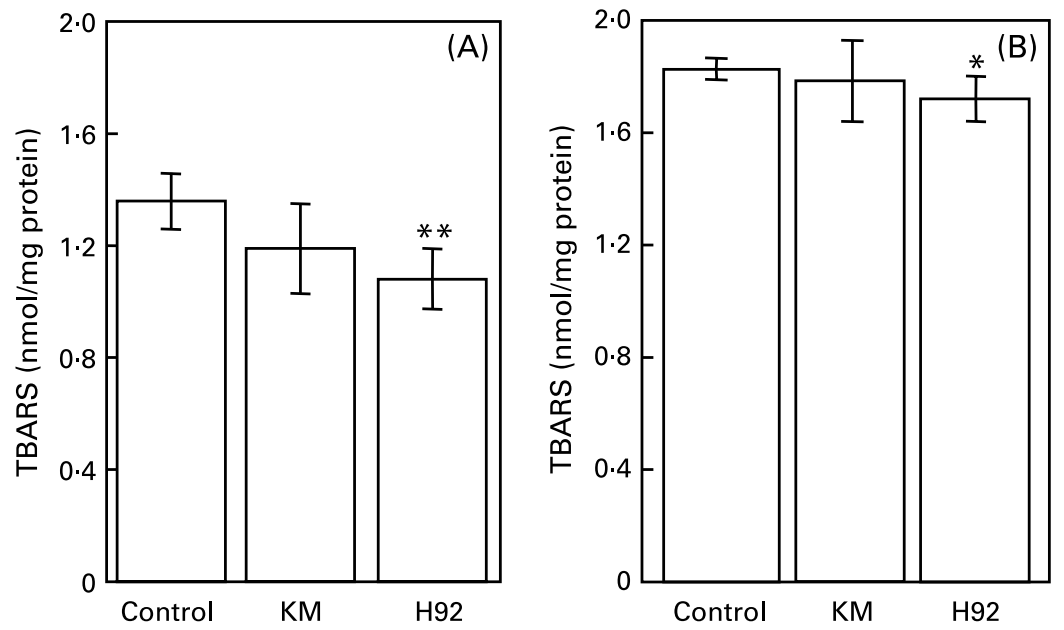

Fig. 5. Thiobarbituric acid reactive substances (TBARS) levels from hepatic homogenate (A) without and (B) treated with 2,2'-azobis (2-amidinopropane) dihydrochloride (AAPH) in rats fed the basal (control), Kitamurasaki (KM) and Hokkai no. 92 (H92) potato flake diets for 4 weeks. Reaction was initiated by the addition of $5 \mathrm{~mm}-\mathrm{AAPH}$ at $37^{\circ} \mathrm{C}$ for $1 \mathrm{~h}$. For details of procedures and diets, see p. pp. 1126-1127 and Table 1. Values are means with their standard deviations depicted by vertical bars (data obtained from five animals). Mean values were significantly different from those of the control group (Student's $t$ test): ${ }^{\star} P<0.05 ;{ }^{* \star} P<0.01$.
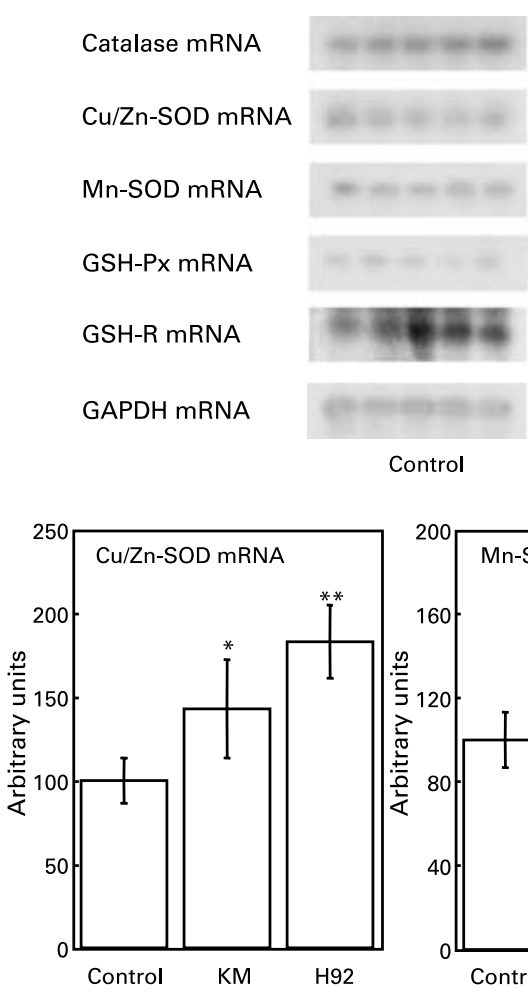

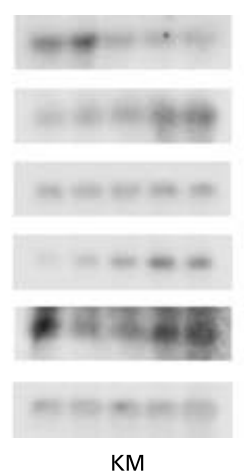

KM

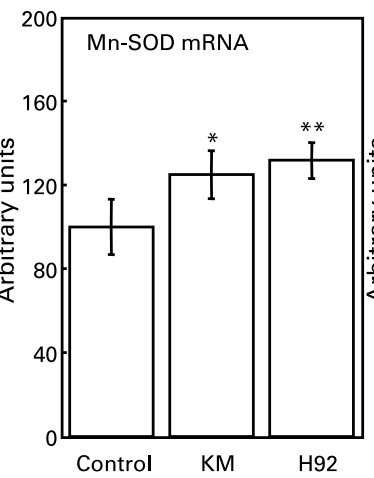

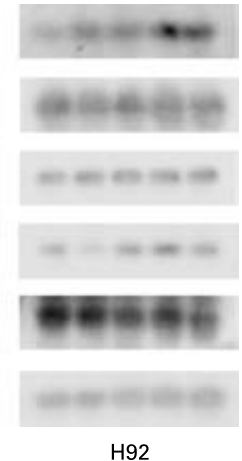
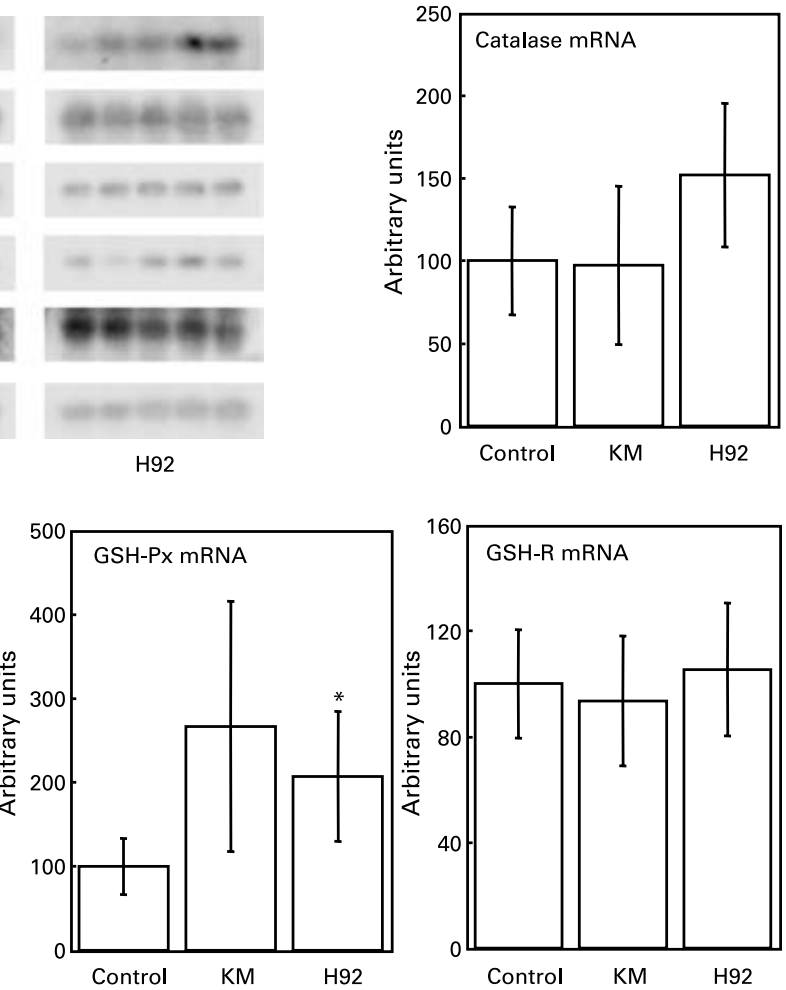

Fig. 6. Hepatic Mn-superoxide dismutase (SOD), Cu/Zn-SOD, catalase, glutathione peroxidase (GSH-Px) and glutathione reductase (GSH-R) mRNA expression in rats fed the basal (control), Kitamurasaki (KM) and Hokkai no. 92 (H92) potato flake diets for 4 weeks. For details of procedures and diets, see pp. $1126-1127$ and Table 1. Values are means with their standard deviations depicted by vertical bars (data obtained from five animals). Mean values were significantly different from those of the control group (Student's $t$ test): ${ }^{*} P<0.05$; ${ }^{\star *} P<0.01$. The values for Mn-SOD, Cu/Zn-SOD, catalase, GSH-Px and GSH-R mRNA are expressed relative to glyceraldehyde-3-phosphate dehydrogenase (GAPDH) mRNA in all groups. Representative samples illustrate mRNA levels measured by RT-PCR and Southern blotting.

H92 potato flake may also contribute to analogous effects on the antioxidant potential in vivo. It is reported that the increase in serum antioxidant potential caused by anthocyanins is due to the stability of intestinal absorption of anthocyanins in acidic media like gastric juice (Passamonti et al. 2003). It has also been suggested that the effect on hepatic lipid peroxidation might be due to anthocyanin derivatives present in the liver (Miyazawa et al. 1999) that scavenge free radicals via the formation of a DNA co-pigmentation complex (Sarma \& Sharma, 1999). In the present study, however, it is unlikely that the effect on serum and liver homogenate of the rats fed purple potato flakes was directly attributable to dietary anthocyanins. 
This is because not only are anthocyanins poorly absorbed by the intestine (Prior, 2003) but also because the antioxidant properties of dietary polyphenols, including anthocyanins, in serum are impaired by hydroperoxide (Tsuda et al. 1998; Halliwell, 2003). In addition, the serum level of flavonoids is usually in the range of $1 \mu \mathrm{M}$ and in the case of anthocyanins may be much lower (Prior, 2003). However H92 potato flakes increased the serum trolox equivalent antioxidant capacity values to approximately $200 \mu \mathrm{M}$ (enhanced from 0.8 to $1.0 \mathrm{mM}$ ). Therefore, the increased serum trolox equivalent antioxidant capacity value in the H92 group may not only be related to increases in dietary polyphenols due to their poor bioavailability. However, it is well known that the serum antioxidant capacity is mostly due to certain antioxidants such as ascorbate, $\alpha$-tocopherol, bilirubin and urate (Benzie \& Strain, 1996; Cao et al. 1998). Augustin (1975) reported a large range of vitamin C content among potato cultivars, varying from 84 to $145 \mathrm{mg} / 100 \mathrm{~g}$ on a dry basis, and Cao et al. (1998) suggested that the increase in serum antioxidant capacity by consumption of strawberries and vitamin $\mathrm{C}$ was related to increases in the serum ascorbate and urate levels in man. Therefore, the increased antioxidant capacity in serum following the intake of purple potato flakes may be attributable to absorbed vitamin $\mathrm{C}$ or enhanced production of uric acid from purine metabolism. However, we do not have data for the serum urate and ascorbate levels.

Owing to limited absorption and conversion to other metabolites (Stahl et al. 2002; Prior, 2003), the antioxidant properties of dietary polyphenols from purple potato flakes may be exerted mainly in the gastrointestinal tract. The consumption of a meal rich in lipids and/or carbohydrates increases the susceptibility of the organism to oxidative damage (Bae et al. 2001; Sies et al. 2005). However, the postprandial oxidative stress is restricted when meals containing excess lipids and/ or carbohydrates are consumed together with foods rich in polyphenols (Natella et al. 2002). This inhibitory action is explained by the fact that during gastrointestinal passage, polyphenols decompose lipid hydroperoxide (Stahl et al. 2002; Sies et al. 2005) and chelate autoxidation-promoting metal ions (Yoshino \& Murakami, 1998). In the present study, scavenging of such adverse food constituents in vivo might have resulted in up-regulation of the expression of antioxidant enzymes (Moskaug et al. 2004; Yeh \& Yen, 2006) and reduction of oxidative damage in the liver (Ramirez-Tortosa et al. 2001). Another possible inhibitory action might be reduced primary or secondary carbohydrate autoxidation products such as glycated proteins in the gastrointestinal tract. Thus, it might also be that the postprandial oxidative damage in the intestinal epithelial cells induced by potato carbohydrate autoxidation products was lower in the present study because the carbohydrate concentrations in purple potato groups (H92, $705 \mathrm{~g} / \mathrm{kg}$ diet; KM, $712 \mathrm{~g} / \mathrm{kg}$ diet) were lower than in the control group $(750 \mathrm{~g} / \mathrm{kg}$ diet $)$. Recently, Yeh \& Yen (2006) reported that hepatic SOD and GSH-Px mRNA expression in rats with phenolic compound supplementation was increased. In the present study, the hepatic Mn-SOD, Cu/Zn-SOD and GSH-Px mRNA expression in the KM or H92 groups was higher than in the control group. Therefore, it is assumed that factors up-regulating the expression of SOD and GSH-Px mRNA of rats following the intake of purple potato flakes may lead to inhibition of hepatic lipid peroxidation, which may be involved in the postprandial oxidative stress induced by potato carbohydrate autoxidation products or putative counteraction by polyphenols present in the gastrointestinal tract (Sies et al. 2005).

In conclusion, the present study suggests that pigmented fractions from purple potato flakes have antioxidant functions with regard to radical scavenging activity and inhibit linoleic acid oxidation in vitro. In addition, H92 potato flakes may indirectly reduce hepatic lipid peroxidation in rats by modulating the expression of hepatic Mn-SOD, Cu/Zn-SOD and GSH-Px mRNA. However, further study is necessary to clarify the antioxidant capacities of purple potatoes in vivo.

\section{Acknowledgements}

We are grateful to Dr Hiroaki Yamauchi (The National Agricultural Research Center for the Hokkaido Region) who kindly offered the potato tubers for this study. This work was supported in part by a grant from the Research and Development Program for New Bio-industry Initiatives of the Biooriented Technology Research Advancement Institution, by a Grant-in-Aid for JSPS Fellows, by a grant from Cooperation of Innovative Technology and Advanced Research in Evolutional Area (CITY AREA), and by a grant from the 21st Century COE Program (A-1), Ministry of Education, Culture, Sports, Science and Technology of Japan.

\section{References}

Afaq F, Saleem M, Krueger CG, Reed JD \& Mukhtar H (2005) Anthocyanin- and hydrolyzable tannin-rich pomegranate fruit extract modulates MAPK and NF-kappaB pathways and inhibits skin tumorigenesis in CD-1 mice. Int J Cancer 113, 423-433.

Association of Official Analytical Chemists (1990) Official Methods of Analysis, 15th ed., Arlington, VA: AOAC.

Auger C, Laurent N, Laurent C, Besancon P, Caporiccio B, Teissedre PL \& Rouanet JM (2004) Hydroxycinnamic acids do not prevent aortic atherosclerosis in hypercholesterolemic golden Syrian hamsters. Life Sci 74, 2365-2377.

Augustin J (1975) Variations in the nutritional composition of fresh potatoes. J Food Sci 40, 1295-1299.

Bae JH, Bassenge E, Kim KB, Kin YK, Kim KS, Lee HJ, Moon KC, Lee MS, Park KY \& Schwemmer M (2001) Postprandial hypertriglyceridemia impairs endothelial function by enhanced oxidant stress. Atherosclerosis 155, 517-523.

Benzie IFF \& Strain JJ (1996) The ferric reducing ability of plasma (FRAP) as a measure of 'antioxidant power': the FRAP assay. Anal Biochem 239, 70-76.

Bradford MM (1976) A rapid and sensitive method for the quantitation of microgram quantities of protein utilizing the principle of protein-dye binding. Anal Biochem 72, 248-254.

Brand-Williams W, Cuvelier ME \& Berset C (1995) Use of a free radical method to evaluate antioxidant activity. Lebensm-Wiss U-Technol 28, 25-30.

Brown CR (2005) Antioxidants in potato. Am J Potato Res 82, $163-172$.

Cao G, Russell RM, Lischner N \& Prior RL (1998) Serum antioxidant capacity is increased by consumption of strawberries, spinach, red wine or vitamin C in elderly women. J Nutr 128, 2383-2390.

Chmielewska Z (1936) Sur les colorants des pommes de terre violette 'Negresse'. Bull Soc Chim 5, 575-588.

Chomczynski P \& Sacchi N (1987) Single-step method of RNA isolation by acid guanidium thiocyanate-phenol-chloroform extraction. Anal Biochem 162, 156-159. 
Eichhorn S \& Winterhalter P (2005) Anthocyanins from pigmented potato (Solanum tuberosum L.) varieties. Food Res Intern 38, 943-948.

Fossen T, Øvstedal DO, Slimestad R \& Andersen ØM (2003) Anthocyanins from a Norwegian potato cultivar. Food Chem 81, 433-437.

Giusti MM \& Wrolstad RE (2001) Characterization and measurement of anthocyanin by UV-visible spectroscopy. In Current Protocols in Food Analytical Chemistry, pp. 1-13 [RE Wrolstad, editor]. Unit $\mathrm{F} 1 \cdot 2 \cdot 1-1 \cdot 2 \cdot 13$.

Hagiwara A, Yoshino H, Ichihara T, Kawabe M, Tamano S, Aoki H, Koda T, Nakamura M, Imaida K, Ito N \& Shirai T (2002) Prevention by natural food anthocyanins, purple sweet potato color and red cabbage color, of 2-amino-1-methyl-6-phenylimidazo [4,5-b] pyridine (PhIP)-associated colorectal carcinogenesis in rats initiated with 1,2-dimethylhydrazine. J Toxicol Sci 27, 57-68.

Han KH, Hashimoto N, Shimada K, Sekikawa M, Noda T, Yanauchi H, Hashimoto M, Chiji H, Topping DL \& Fukushima M (2006) Hepatoprotective effects of purple potato extract against D-galactosamine-induced liver injury in rats. Biosci Biotechnol Biochem 70, 1432-1437.

Halliwell B (2003) Plasma antioxidants: health benefits of eating chocolate? Nature 426, 787 (discussion 788).

Harborne JB \& Grayer RJ (1988) The anthocyanins. In The Flavonoids, pp. 1-20 [JB Harborne, editor]. London: Chapman and Hall.

Jia Z, Tang M \& Wu J (1999) The determination of flavonoid contents in mulberry and their scavenging effects on superoxide radicals. Food Chem 64, 555-559.

Johnson CA (1995) 1995-1996 seed acres reflect more varieties, market shifts. Valley Potato Grower 61, 13-16.

Kähkönen MP \& Heinonen M (2003) Antioxidant activity of anthocyanins and their aglycons. J Agric Food Chem 51, 628-633.

Lewis CE, Walker JRL, Lancaster JE \& Sutton KH (1998) Determination of anthocyanins, flavonoids and phenolic acids in potatoes. I: Coloured cultivars of Solanum tuberosum L. J Sci Food Agric 77, 45-57.

Mazza G, Kay CD, Cottrell T \& Holub BJ (2002) Absorption of anthocyanins from blueberries and serum antioxidant status in human subjects. J Agric Food Chem 50, 7731-7737.

Mitsuda H, Yasumoto K \& Iwami K (1996) Antioxidative action of indolee compounds during the autoxidation of linoleic acid. $J J p n$ Soc Nutr Food Sci 19, 210-214.

Miyazawa T, Nakagawa K, Kudo M, Kayo M \& Someya K (1999) Direct intestinal absorption of red fruit anthocyanins, cyanidin-3glucoside and cyanidin-3-5-diglucoside, into rats and humans. J Agric Food Chem 47, 1083-1091.

Moskaug JO, Carlsen H, Myhrstad M \& Blomhoff R (2004) Molecular imaging of the biological effects of quercetin and quercetin-rich foods. Mech Ageing Dev 125, 315-324.

Natella F, Belelli F, Gentili V, Ursini F \& Scaccini C (2002) Grape seed proanthocyanidins prevent plasma postprandial oxidative stress in humans. J Agric Food Chem 50, 7720-7725.

National Research Council (1996) Guide for the Care and Use of Laboratory Animals. Bethesda, MD: National Institutes of Health.

Ohkawa H, Ohishi N \& Yagi K (1979) Assay for lipid peroxide in animal tissues by thiobarbutric reactions. Anal Biochem 95, $351-358$

Omenn GS (1995) What accounts for the association of vegetables and fruits with lower incidence of cancers and coronary heart diseases? Ann Epidemiol 5, 333-335.
Passamonti S, Vrhovsek U, Vanzo A \& Mattivi F (2003) The stomach as a site for anthocyanins absorption from food. FEBS Lett 544, $210-213$

Pedersen CB, Kyle J, Jenkinson AM, Gardner PT, McPhail DB \& Duthie GG (2000) Effects of blueberry and cranberry juice consumption on the plasma antioxidant capacity of healthy female volunteers. Eur J Clin Nutr 54, 405-408.

Prior RL (2003) Fruits and vegetables in the prevention of cellular oxidative damage. Am J Clin Nutr 78, 570S-578S.

Ramirez-Tortosa C, Andersen OM, Gardner PT, Morrice PC, Wood SG, Duthie SJ, Collins AR \& Duthie GG (2001) Anthocyanin-rich extract decreases indices of lipid peroxidation and DNA damage in vitamin E-depleted rats. Free Radic Biol Med 31, 1033-1037.

Re R, Pellegrini RN, Proteggente A, Pannala A, Yang M \& RiceEvans C (1999) Antioxidant activity applying an improved ABTS radical cation decolorization assay. Free Radic Biol Med 26, 1231-1237.

Reeves PG, Nielsen FH \& Fahey GC Jr (1993) AIN-93 purified diets for laboratory rodents: final report of the American Institute of Nutrition ad hoc writing committee on the reformulation of the AIN-76A rodent diet. $J$ Nutr 123, 1939-1951.

Reyes LF, Miller JC Jr \& Cisneros-Zevallos L (2005) Antioxidant capacity, anthocyanins and total phenolics in purple- and redfleshed potato (Solanum tuberosum L.) genotypes. Am J Potato Res 82, 271-277.

Rodriguez-Saona LE, Giusti MM \& Wrolstad RE (1998) Anthocyanin pigment composition of red-fleshed potatoes. J Food Sci 63, $458-465$.

Sarma AD \& Sharma R (1999) Anthocyanin-DNA copigmentation complex: mutual protection against oxidative damage. Phytochemistry 52, 1313-1318.

Sies H, Stahl W \& Sevanian A (2005) Nutritional, dietary and postprandial oxidative stress. J Nutr 135, 969-972.

Singleton VL, Orthofer R \& Lamuela-Raventós RM (1998) Analysis of total phenols and other oxidation substrates and antioxidants by means of Folin-Ciocalteu reagent. Methods Enzymol 299, 152-178.

Sorenson EJ (1992) Specialty potatoes. Am Veg Grower January, $36-39$.

Stahl W, van den Berg H, Arthur J, et al. (2002) Bioavailability and metabolism. Mol Aspects Med 23, 39-100.

Tsuda T, Horio F \& Osawa F (1998) Dietary cyanidin 3-O-beta-Dglucoside increases ex vivo oxidation resistances of serum in rats. Lipids 33, 583-588.

Tsuda T, Horio F \& Osawa T (2000) The role of anthocyanins as an antioxidant under oxidative stress in rats. Biofactors 13, $133-139$.

Wang H, Cao G \& Prior RL (1997) Oxygen radical absorbing capacity of anthocyanins. J Agric Food Chem 45, 304-309.

Yeh CT \& Yen GC (2006) Induction of hepatic antioxidant enzymes by phenolic acids in rats is accompanied by increased levels of multidrug resistance-associated protein 3 mRNA expression. J Nutr 136, 11-15.

Yoshino M \& Murakami K (1998) Interaction of iron with polyphenolic compounds: application to antioxidant characterization. Anal Biochem 257, 40-44.

Zern TL, Wood RJ, Greene C, West KL, Liu Y, Aggarwal D, Shachter NS \& Fernandez ML (2005) Grape polyphenols exert a cardioprotective effect in pre- and postmenopausal women by lowering plasma lipids and reducing oxidative stress. J Nutr 135, $1911-1917$. 